\title{
A IMPORTÂNCIA DE THREADS NO DESEMPENHO DE APLICAÇÕES
}

\section{Euzébio da Costa Silva ${ }^{1}$ \\ Victor Pereira Ribeiro \\ Susana Brunoro Costa de Oliveira ${ }^{3}$}

Resumo: Com a finalidade de mostrar a presença e a importância de threads para os usuários de computadores, e despertar o interesse, principalmente de estudantes das áreas relacionadas, foi construída uma tabela de comparação do tempo de processamento gasto, foram usados códigos escritos na linguagem $C_{++}$, que implementam algoritmos de ordenação (Bubble Sort, Insertion Sort e Selection Sort), e para cada algoritmo foi feita a ordenação de um vetor de 100000 (cem mil) posições. Também é importante citar que foram feitos testes com 5 e 9 vetores, afim de obter resultados mais expressivos. Por último foram feitos testes com threads, seguindo os mesmos moldes dos anterior. Os testes feitos em dois computadores diferentes mostraram um ganho notável para os threads, 48,34\% e 67,46\%, valores significativos para aplicações que requerem mais desempenho.

Palavras-chave: Importância de threads; Usuário de computadores; Tempo de processamento; Testes com threads.

\footnotetext{
${ }^{1}$ Análise e Desenvolvimento de Sistemas/IFES-Campus de Alegre, Brasil. E-mail: euzebioprogramacao@gmail.com.

${ }^{2}$ Análise e Desenvolvimento de Sistemas/IFES - Campus de Alegre, Brasil. E-mail: victor3ifes@gmail.com.

3 Processamento de Dados/Pontifícia Universidade Católica do Rio de Janeiro, Brasil. E-mail: sbrunoro@ifes.edu.br.
} 